\title{
Self-management practices of smokers with asthma and/or chronic obstructive pulmonary disease: a cross-sectional survey
}

\author{
Claire Hayes-Watson ${ }^{1,2^{*}}$, Henry Nuss ${ }^{1}$, Tung Sung Tseng ${ }^{1}$, Nereida Parada ${ }^{3}$, Qingzhao Yu ${ }^{1,4}$, Michael Celestin', \\ Danelle Guillory ${ }^{1}$, Krysten Winn ${ }^{1}$ and Sarah Moody-Thomas ${ }^{1}$
}

\begin{abstract}
Background: Adherence to self-management recommendations is critical for patients with chronic disease. Compared to nonsmokers, smokers with conditions such as diabetes, HIV, and heart disease are less likely to adhere to provider recommendations. Regarding lung disease, asthma and COPD can be caused and/or exacerbated by smoking, however little is known on the relationship between adherence and smoking status in these patients. The purpose of this study was to characterize the relationship between smoking status and adherence to multiple measures of self-care- including medication taking, medication filling, appointment keeping, yearly vaccinations, carrying medical supplies, and healthcare utilization- in patients with asthma and/or COPD. In addition to smoking status, we also included an examination of these measures by race/ethnicity, gender, and diagnosis.

Methods: This study employed a cross-sectional design on a convenience sample of $n=84$ patients (40-64 years old) with a diagnosis of asthma and/or COPD. The study was conducted between November 2015 and February 2016 in the waiting rooms of the outpatient pulmonary clinics at the University Medical Center of New Orleans. Patients completed surveys while awaiting their clinic appointments. Smoking status, gender, race, and diagnosis were explored as predictors of adherence using descriptive statistics, chi square, and regression analyses.

Results: Compared to nonsmokers, smokers were less adherent to medication filling ( $p<0.0001)$, medication taking $(p=0.04)$, and having yearly vaccinations than nonsmokers $(p=0.003)$. Independent of smoking status, differences across self-care measures were also found based on respondent diagnosis, race, and gender.

Conclusion: Smoking was associated with lower levels of adherence across multiple measures of self-care. By identifying self-management practices that are most difficult for smokers to follow, researchers can develop interventions that target these behaviors. Future studies should further this research by exploring reasons for poor adherence in smokers as well as address barriers that inhibit self-care.
\end{abstract}

Keywords: Adherence, Tobacco use, Asthma, COPD, Disease self-management, Healthcare utilization, Vaccinations

\section{Background}

Smoking is the leading cause of chronic disease in the US including $90 \%$ of lung cancers, $80 \%$ of all chronic lung conditions, and $20 \%$ of all cardiovascular disease [8]. Asthma and chronic obstructive pulmonary disease (COPD) affect $8.2 \%$ and $6.3 \%$ of US adults, respectively.

\footnotetext{
*Correspondence: Cehwats1@email.unc.edu

'Louisiana State University Health Sciences Center, School of Public Health,

Behavioral and Community Health Science, New Orleans, LA, USA

2University of North Carolina at Chapel Hill, Eshelman School of Pharmacy,

Chapel Hill, NC, USA

Full list of author information is available at the end of the article
}

Nonetheless, although smoking is known to worsen outcomes for these patients, $25 \%$ of asthmatics and $51 \%$ of COPD patients continue to smoke post diagnosis [33]. Compared to non-smokers, smokers with these conditions experience increased hospitalizations, diseaserelated complications, and are more likely to die from their chronic conditions [33].

Poor treatment adherence, a lead contributor to poor outcomes in some patient groups, is described as a growing problem in chronic disease literature [28]. Poor adherence is associated with sociodemographic risk 
factors including low educational attainment, low income status, race/ethnicity as well as behavioral risk factors including alcohol abuse, drug use, and tobacco use $[1,20,22]$. Studies evaluating adherence in smokers with chronic disease report that tobacco users are less likely to follow self-management recommendations than nonsmokers or former smokers [1, 6, 22, 35]. Nonetheless, in these studies, the examination of treatment adherence is largely limited to the ability of patients to take medications as prescribed. For patients with asthma and/or COPD, self-care programs may include multiple recommendations such as medication taking, yearly flu and pneumonia vaccinations, carrying medical supplies for sudden exacerbations, reducing or quitting tobacco use, attending follow-up appointments, or attending pulmonary rehab. As part of guideline-based care, physicians may make these and other recommendations for patients to adopt as part of their self-management care plan $[12,26]$.

Although asthma and COPD are caused and/or exacerbated by tobacco use, the relationship between smoking status and adherence in these patients has not been previously studied. In this study, researchers sought to characterize the relationship between smoking and treatment adherence in patients with asthma and/or COPD. This included an examination of adherence based on several measures of self-care including medication taking, medication filling, appointment attendance, carrying medical supplies, yearly vaccinations, and healthcare utilization (i.e., emergency room visits and hospitalizations). In addition to examining adherence in smokers, researchers also sought to explore additional patient-level factors including race, gender, and diagnosis.

\section{Methods}

\section{Survey instrument}

The Asthma and COPD Patient Adherence Survey consisted of 43 Likert and multiple-choice items created by study researchers and adapted from the Tobacco Control Initiative Patient Survey [25] and the Medical Outcomes Survey [17]. The development of new survey items was informed by clinical practice guidelines for the treatment of asthma and COPD [12, 26]. The study instrument was validated using the content validity expert panel review process [21]. Experts $(n=8)$ in clinical pulmonology, allergy, pharmacy, health education, nursing, and primary care participated in the validation assessment. Based on content validity index (CVI) methods developed by Lawshe [21], total survey content validity was calculated at CVI $=0.87$, where CVI $>0.80$ is acceptable for inclusion [21]. The survey allowed researchers to collect primary outcome measures of self-reported adherence including medication filling, medication taking, appointment attendance, carrying medical supplies, yearly flu and/or pneumonia vaccinations, emergency room (ER) visits, hospitalizations, and missed appointments within the past 12 months. Validation and preference of self-reported adherence is documented in clinical literature [7, 11, 18]. Patient level factors including demographic characteristics, tobacco history, and diagnosis were also collected.

\section{Recruitment and data collection}

Approval for this study was obtained from the Institutional Review Board at Louisiana State University Health Sciences Center and Tulane University School of Medicine (Approval \#9138). This study employed a crosssectional design on a non-probability, convenience sample of adult patients (40-64 years old) with asthma and/or COPD. Patients were excluded if they were unable to complete the survey on their own. Data collection occurred between November 2015 and February 2016 in the pulmonary clinic waiting areas of University Medical Center of New Orleans (UMCNO), a state hospital serving Louisiana's indigent population. All patients arriving for clinic appointments were screened using a two item query to confirm age and a diagnosis of either asthmaonly (AO), COPD-only (CO), or a combined diagnosis of asthma and COPD (AC). Eligible patients completed the survey while waiting for their appointment. The screening and survey process were anonymous as no patient identifiers were collected. One goal of recruitment was to enroll an equal number of smokers and nonsmokers into the study. Study staff disseminated and collected completed screeners and surveys.

\section{Data analysis}

Statistical Analysis Software (SAS) 9.4 was used to analyze data. Descriptive statistics of patient characteristics including race, gender, medical history, and tobacco history were performed. Chi square analysis was also conducted to examine associations among predictors (i.e., race, gender, diagnosis and smoking status). Bivariate analysis was also performed using chi square analysis to explore associations between predictors and measures of adherence. Multivariate logistic regression was conducted to further test predictor effects. Interactions among predictors were also explored. Odds ratios for predictors were constructed in order to understand the direction of relationships.

\section{Results}

\section{Sample characteristics}

Of the 239 patients screened, 91 (38.1\%) were determined eligible based on age and diagnosis criteria. More specifically, 62 patients did not meet age criteria (40-64 years), while 86 patients did not have a diagnosis of 
asthma and/or COPD. Of the $n=91$ eligible patients, 88 (96.7\%) consented to take the survey, and $n=84 \mathrm{com}-$ pleted the survey in full. Baseline characteristics of the study sample are reported in Table 1 . The age of sampled patients ranged from 41 to 64 years $($ Mean $=56.07$, $\mathrm{SD}=5.25)$. Respondents were predominately White/ Caucasian (45.1\%) and Black/African American (46.3\%), with a small portion identifying as Other (8.4\%) which included Native Hawaiian/Other Pacific Islander $(n=2)$, American Indian/Alaskan Native $(n=3)$, or Hispanic $(n=2)$. These participants were combined with Black participants into one measure "Black and Other Races" (54.9\%). Most patients (91.8\%) reported a household income below $133 \%$ of the federal poverty level and $74.7 \%$ of respondents had less than a high school diploma or GED.

\section{Smoking history}

Participant history of tobacco use is presented in Table 2. The majority of the sample $(62.65 \%, n=52)$ identified as being "current smokers" (i.e., those who reported smoking 100 cigarettes in their lifetime, and currently smoke). Respondents who reported smoking 100 cigarettes in their lifetime but did not currently smoking were defined as former smokers $(n=17)$. Former smokers and never smokers (individuals who have never smoked 100 cigarettes in their lifetime) were dichotomized into one measure, nonsmokers $(n=31)$, for purposes of this research. Past studies have supported this approach, as former smokers and never-smokers are behaviorally and clinically similar in adherence studies $[6,22,31]$.

\section{Race, gender and smoking status and diagnosis}

Smoking rates were not different between White males and "Black and Other" males $(p=0.4646)$. Differences were also not found between White and "Black and Other" females. However when comparing "Black and Other" males to "Black and Other" females, males were more likely to be smokers $(p=0.056)$. Regarding patient diagnosis, current smokers were more likely to have a combined asthma/COPD (AC) (46.15\%) diagnosis, than COPD-only (CO) (28.85\%) or asthma-only (AO) participants $(25.0 \%)$.

\section{Analysis of adherence measures and predictors}

Associations between adherence measures and predictors are shown in Table 3. When controlling for gender, smoking status and diagnosis were significant independent predictors of medication filling ( $p=0.0023$ and $p=0.0008$, respectively). Smoking was negatively associated with having all medications filled, $\mathrm{OR}=0.085$, 0.018-0.400. AO respondents were more likely to have all medications filled compared to those patients with COPD (CO) $(p=0.0005)$. Patients with asthma
Table 1 Demographic, Medical, and Tobacco Characteristics $(n=84)$

\begin{tabular}{|c|c|c|}
\hline & No. & (\%) \\
\hline Age & $M=56.07$ & $\mathrm{SD}=5.25$ \\
\hline \multicolumn{3}{|l|}{ Gender } \\
\hline Males & 39 & $46.43 \%$ \\
\hline Females & 45 & $53.57 \%$ \\
\hline \multicolumn{3}{|l|}{ Race } \\
\hline White or Caucasian & 37 & $45.12 \%$ \\
\hline Black or African American & 38 & $46.34 \%$ \\
\hline Other ${ }^{a}$ & 7 & $8.54 \%$ \\
\hline \multicolumn{3}{|l|}{ Diagnosis } \\
\hline Asthma & 27 & $32.14 \%$ \\
\hline COPD & 31 & $36.90 \%$ \\
\hline Asthma/COPD & 26 & $30.95 \%$ \\
\hline \multicolumn{3}{|l|}{ Smoking Status ${ }^{\mathrm{b}}$} \\
\hline Smokers & 52 & $62.65 \%$ \\
\hline Nonsmokers & 31 & $37.35 \%$ \\
\hline \multicolumn{3}{|l|}{ Education Completed } \\
\hline Never attended/Kindergarten only & 1 & $1.27 \%$ \\
\hline Grades 1 through 8 (Elementary) & 3 & $3.80 \%$ \\
\hline Grades 9 through 11 (Some high school) & 20 & $25.32 \%$ \\
\hline Grade 12 or GED (High School Graduate) & 35 & $44.30 \%$ \\
\hline $\begin{array}{l}\text { College } 1 \text { year to } 3 \text { (Some college } \\
\text { or Tech. School) }\end{array}$ & 15 & $18.99 \%$ \\
\hline College 4 years or more (College graduate) & 5 & $6.33 \%$ \\
\hline \multicolumn{3}{|l|}{ Household Income ${ }^{c}$} \\
\hline Less than $\$ 10,000$ & 16 & $23.88 \%$ \\
\hline$\$ 10,000-14,999$ & 18 & $26.87 \%$ \\
\hline$\$ 15,000-19,999$ & 30 & $44.78 \%$ \\
\hline$\$ 20,000$ or more & 3 & $4.48 \%$ \\
\hline Household Size ${ }^{c}$ & $M=2.70$ & $\mathrm{SD}=1.55$ \\
\hline \multicolumn{3}{|l|}{$\%$ Federal Poverty Level ${ }^{c}$} \\
\hline$<100 \%$ & 36 & $59.02 \%$ \\
\hline $100 \%-133 \%$ & 20 & $32.79 \%$ \\
\hline $134 \%-150 \%$ & 4 & $6.56 \%$ \\
\hline$>150 \%$ & 1 & $1.64 \%$ \\
\hline
\end{tabular}

NOTE: ${ }^{2}$ Native Hawaiian/Other Pacific Islander, American Indian or Alaskan Native, those identifying as Hispanic, and Other

${ }^{b}$ Smoking status: current smokers include those respondents who indicate smoking 100 cigarettes in their lifetime, and who indicate that they currently smoke every day or some days. Nonsmokers include those who have never smoked 100 cigarettes in their lifetime (never smokers) as well as those who have smoked 100 cigarettes but do not currently smoke (former smokers) and have not smoked within last 6 months or longer

Indicates less than $80 \%$ response rate for item

were also more likely than $\mathrm{AC}$ patients to have all medications filled. Smoking status was the only predictor of taking a medication, as smokers were less 
Table 2 Tobacco Characteristics of the Study Sample $(n=83)$

\begin{tabular}{lll}
\hline & No. & $(\%)$ \\
\hline Lifetime Tobacco Use $^{\text {a }}$ & & \\
Yes & 69 & $83.13 \%$ \\
No & 14 & $16.87 \%$ \\
Current smoking status & & \\
$\quad$ Every day & 27 & $32.53 \%$ \\
$\quad$ Some days & 25 & $30.12 \%$ \\
$\quad$ Not at all & 31 & $37.35 \%$ \\
Smoking status & \\
$\quad$ Nonsmokers & & \\
$\quad$ Smokers & 31 & $37.35 \%$ \\
Smoking duration (Years) & 52 & $62.65 \%$ \\
Average cigarettes smoked per day? & $\mathrm{M}=33.05$ & $\mathrm{SD}=10.05$ \\
\hline
\end{tabular}

NOTE: a Respondents who indicated smoking 100 cigarettes in their lifetime ${ }^{\text {b }}$ "Smokers" include those respondents who indicate smoking 100 cigarettes in their lifetime, and who indicate that they currently smoke every day or some days. "Nonsmokers" include those who have never smoked 100 cigarettes in their lifetime (never smokers) as well as those who have smoked 100 cigarettes but do not currently smoke

likely to take medications as prescribed compared to nonsmokers (OR $=0.333,0.1015-0.9320, p=0.032)$.

Yearly flu and pneumonia vaccines were independently predicted by smoking status and diagnosis $(p=0.0085$ and $p=0.0016$, respectively). Smokers were less likely to have a flu vaccine than nonsmokers within the sample ( $\mathrm{OR}=0.152,0.444-0.526, p=0.003)$. Respondents with $\mathrm{AC}$ were more likely to have flu and pneumonia vaccinations than patients with $\mathrm{AO}$ or $\mathrm{CO}$ respondents $(\mathrm{OR}=10.399,2.408-44.915, p=0.0017)$.

Race was the only significant predictor of missed appointments. "Black and Other" respondents were more likely to miss an appointment than Whites $(\mathrm{OR}=4.61$, $1.699-12.510, p=0.0027$. Race and diagnosis independently predicted ER visits $(p=0.0245$ and $p=0.0043$, respectively), however when controlling for gender, race and diagnosis also predicted hospital admissions ( $p=$ 0.0177 and $p=0.0063$, respectively). Whites were more likely to have ER visits and hospital admissions than Blacks and Others $(\mathrm{OR}=0.133,0.399-0.449, p=0.0012$ and $\mathrm{OR}=0.119,0.033-0.428, p=0.0011$, respectively). Diagnosis was also a significant predictor of ER visits and hospital admissions. Compared to patients with COPD, patients with asthma were less likely to have an ER visit $(\mathrm{OR}=0.222,0.058-0.853, p=0.0285)$ or be admitted to the hospital $(\mathrm{OR}=0.037,0.004-0.351, p=$ 0.004). Differences were not noted in these measures between patients with $\mathrm{AC}$ and $\mathrm{CO}$ diagnoses.

Gender was the only significant predictor of medical appointment attendance as being a female respondent was positively associated with attending medical appointments (OR $=7.143,1.452-35.137, p=0.0156$ ).
Interactions were explored in this analysis however were not significant.

\section{Discussion \\ Smoking status and adherence}

Reasons for poor medication filling and taking in smokers may be pharmacological. Inhaled corticosteroids (ICS) are commonly prescribed for the daily management of asthma and COPD. ICS resistance is a condition that affects smokers, making them less resistant to the therapeutic effects of their ICS medications $[4,5,16]$. Therefore, if smokers do not feel their medication is reducing or alleviating symptoms, they may not fill or take their medications as recommended. Researchers have also investigated poor vaccination efficacy in smokers, although a consensus has not been determined in this area [10].

Compared to nonsmokers, smokers may also incur more health-related costs. Smokers often suffer with uncontrolled asthma or COPD requiring more costly, higher dosed therapies that are sometimes not covered by health plans. Additionally, smokers may feel less financially stable than nonsmokers due to increased spending on tobacco products [3]. In one study evaluating tobacco spending in adults, those individuals with the greatest level of nicotine dependence not only spent the most on cigarettes each month, but were also more likely to go without their basic living needs [3].

Flu and pneumonia vaccinations are highly recommended for patients with chronic lung disease as diseased lungs become less resilient to the effects of these viruses over time [12, 26]. However, smokers may be less engaged in their self-care, perhaps even avoiding preventive and wellness services such as vaccinations. This is evident as an association between active smoking and low adoption of health promoting behaviors, such as balanced eating and exercise, are found in the literature $[15,29]$. One study even attributed such behavioral differences to varying personality types with smokers being more impulsive, less agreeable, and less cooperative than nonsmokers [2].

\section{Adherence by race and gender}

Compared to males, female respondents were more likely to attend their asthma and/or COPD related visits as recommended. Women are often described as better self-managers of their chronic conditions and report being more satisfied and engaged with their provider and care plan [13, 30]. In some studies, women also expressed a preference to be informed decision makers of their care and were more likely to play an active role in physician encounters than men [13, 30]. 
Table 3 Race, Gender, Diagnosis and Smoking Status as Predictors of Adherence $(n=82)$

\begin{tabular}{|c|c|c|c|c|c|}
\hline Measure & Predictors & Comparison Group $^{a}$ & OR & $95 \% \mathrm{Cl}$ & $p$ \\
\hline \multirow[t]{5}{*}{$\overline{\text { Medication Filling }^{b}}$} & Smoking Status & & & & \\
\hline & & Smokers & 0.085 & $0.018-0.400$ & 0.0023 \\
\hline & Diagnosis & & & & \\
\hline & & Asthma & 28.628 & $4.346-188.592$ & 0.0005 \\
\hline & & AsthmaCOPD & 1.323 & $0.285-6.138$ & 0.7211 \\
\hline \multirow[t]{2}{*}{ Missed Appointments } & Race & & & & \\
\hline & & Black \& Other Races & 4.61 & $1.699-12.510$ & 0.0027 \\
\hline \multirow[t]{5}{*}{ ER visits } & Race & & & & \\
\hline & & Black \& Other Races & 0.133 & $0.039-0.449$ & 0.0012 \\
\hline & Diagnosis & & & & \\
\hline & & Asthma & 0.278 & $0.072-1.065$ & 0.0618 \\
\hline & & AsthmaCOPD & 4.315 & $1.248-14.924$ & 0.0209 \\
\hline \multirow[t]{5}{*}{ Hospital Admissions ${ }^{b}$} & Race & & & & \\
\hline & & Black \& Other Races & 0.119 & $0.33-0.428$ & 0.0011 \\
\hline & Diagnosis & & & & \\
\hline & & Asthma & 0.046 & $0.005-0.442$ & 0.0077 \\
\hline & & AsthmaCOPD & 2.397 & $0.674-8.522$ & 0.1766 \\
\hline Take a medication (including Inhalers) & Smoking Status & Smokers & 0.333 & $0.1015-0.9320$ & 0.032 \\
\hline \multirow[t]{3}{*}{ Carrying Medications and Supplies } & Diagnosis & & & & \\
\hline & & Asthma & 2.2 & $0.324-4.444$ & 0.1618 \\
\hline & & AsthmaCOPD & 0.273 & $0.080-0.931$ & 0.013 \\
\hline \multirow[t]{3}{*}{ Yearly Flu Pneumonia Vaccines } & Smoking Status & Smokers & 0.152 & $0.444-0.526$ & 0.003 \\
\hline & Diagnosis & Asthma & 0.73 & $0.207-2.572$ & 0.6242 \\
\hline & & AsthmaCOPD & 10.399 & $2.408-44.915$ & 0.0017 \\
\hline Attending Medical Appointments ${ }^{c}$ & Gender & Females & 7.143 & $1.452-35.137$ & 0.0156 \\
\hline
\end{tabular}

NOTE: Significance at $p<0.05$; Logistic regression performed to identify multiple predictors of adherence

${ }^{a}$ Reference groups for variables include, smoking status $=$ nonsmokers, race $=$ White, gender $=$ male, diagnosis $=C O P D$

${ }^{\mathrm{b}}$ Controlling for gender

${ }^{\mathrm{c} C o n t r o l l i n g ~ f o r ~ s m o k i n g ~ s t a t u s ~}$

Regarding race, Whites in our study had higher ER visit and hospitalization rates but Blacks and Others were more likely to miss their appointments. This is similar to one study describing appointment nonadherence in a cohort of African American patients with poorly controlled hypertension [27]. Reasons for missed appointments in these patients included access to care as well as poorer knowledge and attitudes towards care [27]. Although Whites had higher ER visit and hospitalization rates [24], this may be due to the group's ability to recognize symptoms and seek out immediate care [9]. Additionally, hospital admissions have even been described as "protective factors", possibly even motivating patients to adhere after being hospitalized [32].

\section{Adherence by diagnosis}

Differences in diagnosis were associated with varying levels of adherence across several measures including medication filling, ER visits, hospitalizations, carrying medications, and having a yearly flu and/or pneumonia vaccination. Excluding vaccinations, patients with an $\mathrm{AO}$ diagnosis had higher levels of adherence across these measures compared to patients with $\mathrm{CO}$ and $\mathrm{AC}$ diagnoses. Unlike COPD, asthma is non-progressive and symptoms are largely reversible with pharmacotherapy [26]. Patients with AO may experience overall fewer symptoms and can use therapies to quickly alleviate symptoms compared to those with $\mathrm{CO}$ or AC.

Patients with an AO diagnosis may also have less medication than those with COPD. In one study [19] those patients with multiple medications were significantly less likely to adhere than patients prescribed only one medication. Depending on level of severity, patients with COPD may have twice as many medications $[12,26]$. Because asthma is largely diagnosed in childhood [26], asthmatics may also be more accustomed to managing a chronic lung condition than those with $\mathrm{CO}$ which is 
typically diagnosed in late adulthood. Additionally, compared to patients with $\mathrm{AO}$, the progressive nature of COPD often leads those affected to disability and even oxygen dependence [12]. These patients may therefore encounter more physical barriers to self-care than those managing asthma alone.

Within our sample, patients with a combined diagnosis $(\mathrm{AC})$ were more likely to have a vaccination than those with $\mathrm{AO}$ or $\mathrm{CO}$. Patients with this combined diagnosis are known to experience more severe symptoms than those with only asthma or COPD [12]. These patients may frequent the clinic more often, and therefore have greater access to preventive services such as vaccinations.

\section{Limitations}

Our study was limited to the use of patient self-reported data. We therefore lacked information on lung function in order to confirm diagnoses as well as pharmacy data to track medication filling. Although research supports the validity of patient report in measuring adherence [18], the absence of objective measures does require that we depend solely on patient's responses from which to draw conclusions between smokers and nonsmokers. Past studies describe an association between smoking and increased depressive symptoms [14]. Studies also indicate that depression is a risk factor for poor adherence in patients with chronic disease [14, 23, 34]). We did not measure depressive symptoms in our study, however we acknowledge the potential impact of depression on self-care.

\section{Conclusion}

This was the first study to examine the relationship between adherence and smoking in patients with asthma and/or COPD. This was also the first study to examine adherence in smokers across multiple measures of selfcare in addition to medication taking. Through various analyses we discovered that some areas of self-care were not significantly different between smokers and nonsmokers, however differences did exist by certain patient-level factors such as respondent gender, race, and diagnosis.

Results of this study may be used to tailor care for smokers with asthma and/or COPD. Now that we have identified areas of poor adherence in this group, clinicians may develop targeted interventions such as patient counseling services to improve medication compliance and vaccinations in smokers. Investigators may further this research by examining why differences in adherence exist between smokers and nonsmokers. For example, a patient-focused, qualitative study may provide a platform for smokers to express their treatment preferences as well as identify barriers they experience which inhibit their self-care.

Results of this study may also inform the direction of new clinical research focused on smokers with chronic disease. Far too often, smokers are excluded from clinical trials for potential therapies or interventions. This study provides support for the inclusion of smokers in trials as considerations for poor adherence should be examined for all patient groups. Being that smokers make up a substantial proportion of asthma and COPD patients, their needs should also be considered in the development of new therapies.

\begin{abstract}
Acknowledgements
The authors would like to thank the Louisiana State University Health Sciences Center School of Public Health, the Louisiana Tobacco Control Initiative, University Medical Center of New Orleans, and the Louisiana Cancer Research Consortium and the LSUHSC Innovation Resource Center, and University of North Carolina at Chapel Hill, Eshelman School of Pharmacy's Division of Patient Outcomes and Policy for continued support and guidance in the development of this manuscript.
\end{abstract}

\section{Funding}

This study was supported by a contract (CFMS no. 599454) from the Louisiana Cancer Research Consortium (http://www.louisianacancercenter.org). The funders had no role in study design, data collection and analysis, decision to publish, or preparation of the manuscript. We acknowledge the contributions made by the local Tobacco Control Initiative field staff and the cooperation of the Louisiana State University Health Care Services Division.

Availability of data and materials

Please contact author for data requests.

\section{Authors' contributions}

CHW had full access to the study data and takes responsibility for the integrity of the data and accuracy of the data analysis. She also contributed substantially to the study design, data analysis, interpretation, and led the writing of this manuscript. HN, TTS, NP, QY, MC, DG, KW, and SMT contributed substantially to the development of this study, data analysis, and continuous drafting and editing of this manuscript. These authors also read and approved this final draft for submission.

\section{Competing interests}

Claire Hayes Watson: The author has no competing or conflicts of interest to report.

Henry Nuss: The author has no competing or conflicts of interest to report. Tung Sung Tseng: The author has no competing or conflicts of interest to report. Q. Yu: The author has no competing or conflicts of interest to report.

Nereida Parada: The author has no competing or conflicts of interest to report. Michael Celestin: The author has no competing or conflicts of interest to report. Danelle Guillory: The author has no competing or conflicts of interest to report. Krysten Winn: The author has no conflicts of interest to report.

Sarah Moody-Thomas: The author has no competing or conflicts of interest to report.

\section{Consent for publication}

Not applicable.

Ethics approval and consent to participate

Ethics approval for this study was obtained from the Institutional Review Boards of Tulane University and Louisiana State University Health Sciences Center, Lead IRB (\#9138). A waiver of documentation of consent was also approved for this study.

Notation of prior abstract/presentation

These findings have not been presented or published previously. 


\section{Studies involving animals}

Not applicable

\begin{abstract}
Author details
'Louisiana State University Health Sciences Center, School of Public Health, Behavioral and Community Health Science, New Orleans, LA, USA. University of North Carolina at Chapel Hill, Eshelman School of Pharmacy, Chapel Hill, NC, USA. ${ }^{3}$ Tulane University Health Sciences Center, Section of Pulmonary Disease, Critical Care \& Environmental Medicine New Orleans, New Orleans, LA, USA. ${ }^{4}$ Louisiana State University Health Sciences Center, School of Public Health, Biostatistics New Orleans, New Orleans, LA, USA
\end{abstract}

Received: 26 October 2016 Accepted: 25 January 2017 Published online: 15 March 2017

\section{References}

1. Aggarwal B, Mosca L. Lifestyle and psychosocial risk factors predict nonadherence to medication. Ann Behav Med. 2010;40(2):228-33.

2. Axelsson $M$, Emilsson $M$, Brink $E$, Lundgren J, Toren $K$, Lotvall J. Personality, adherence, asthma control and health-related quality of life in young adult asthmatics. Respir Med. 2009;103(7):1033-40.

3. Baggett T, Rigotti N, Campbell E. Cost of smoking among homeless adults, N Engl J Med. 2016;374(7):697-8.

4. Barnes PJ. Corticosteroid resistance in patients with asthma and chronic obstructive pulmonary disease. J Allergy Clin Immunol. 2012;131:636-45.

5. Boulet LP, Deschesnes F, Chaboillez S, Lemiere C. Protocol: influence of budesonide and budesonide/formoterol on asthma control in smoking asthmatic adults. Open Respir Med J. 2010;4:51-7.

6. Cassidy S, Turnbull S, Gardani M, Kirkwood K. Attendance at pulmonary rehabilitation classes: an exploration of demographic, physiological, and psychological factors that predict completion of treatment. Chron Respir Dis. 2014;11(2):95-102

7. Catz SL, Jack LM, McClure JB, Javitz HS, Deprey M, Zbikowski SM, Swan GE. Adherence to varenicline in the COMPASS smoking cessation intervention trial. Nicotine Tob Res. 2011;13(5):361-8.

8. Centers for Disease Control and Prevention [Internet]. Vital Signs: Asthma in the US. 2013. Last accessed 2016 August 1. Available from http://www.cdc. gov/NitalSigns/Asthma/.

9. Dickson V, Knalf G, Wald J, Riegel B. Racial differences in clinical treatment and self-care behaviors of adults with chronic heart failure. J Am Heart Assoc. 2015;4(4):e001561.

10. Feng $Y$, Kong $Y$, Barnes PF, Huang F-F, Klucar P, Wang X, Shams $H$. Exposure to cigarette smoke inhibits the pulmonary $T$-cell response to influenza virus and mycobacterium tuberculosis. Infect Immun. 2011;79(1):229-37.

11. Garfield S, Clifford S, Eliasson L, Barber N, Wilson A. Suitability of measures of self-reported medication adherence for routine clinical use: a systematic review. BMC Med Res Methodol. 2011;11:149.

12. Global Initiative for Chronic Obstructive Lung Disease [Internet]. Pocket Guide to COPD Diagnosis, Management, and Prevention: A Guide for Health Care Professionals. Accessed 1 August 2016. Available from: http://goldcopd. org/pocket-guide-copd-diagnosis-management-prevention-2016/.

13. Goldberg $\mathrm{H}$, Shorten A. Patient and provider perceptions of decision making about use of epidural analgesia during childbirth: A thematic analysis. J Perinatal Education. 2014;23(3):142-50.

14. Grenard JL, Munjas BA, Adams JL, Suttoro M, Maglione M, McGlynn EA, Gellad WF. Depression and medication adherence in the treatment of chronic diseases in the United States: a meta-analysis. 2011.

15. Haibach J, Homish G, Giovino G. A longitudinal evaluation of fruit and vegetable consumption and cigarette smoking. Nicotine Tob Res. 2013; 15(2):355-63.

16. Hayes $\mathrm{C}$, Nuss $\mathrm{H}$, Tseng T, Moody-Thomas S. Use of asthma control indicators in measuring inhaled corticosteroid effectiveness in asthmatic smokers: a systematic review. J Asthma. 2015;52(10):996-1005.

17. Hays RD, Shapiro MF. An overview of generic health-related quality of life measures for HIV research. Quality of Life Research. 1992;1:91-7.

18. Jimmy $B$, Jose J. Patient medication adherence: measures in daily practice. Oman Med J. 2011:26(3):155-9.

19. Kamran A, Sadeghieh A, Biria M, Malepour A, Heydari H. Determinants of patient's adherence to hypertension medications: application of health belief model among rural patients. Ann Med Health Sci Res. 2014;4(6):922-7.
20. Land SR, Cronin WM, Wickerham DL, Costantino JP, Christian NJ, Klein WM, Ganz PA. Cigarette smoking, obesity, physical activity, and alcohol use as predictors of chemoprevention adherence in the national surgical adjuvant breast and bowel project p-1 breast cancer prevention trial. Cancer Prev Res. 2011;4(9):1393-400.

21. Lawshe $\mathrm{CH}$. A quantitative approach to content validity. Personnel Psychol. 1975;28:563-75

22. Liberman JN, Lichtenfeld MJ, Galaznik A, Mastey V, Harnett J, Zou KH, Leader JB, Kirchner HL. Adherence to varenicline and associated smoking cessation in a community based setting. J Manag are Pharm 2013:19(2):125-31.

23. Mausbach B, Schwab R, Irwin S. Depression as a predictor of adherence to adjuvant endocrine therapy (AET) in women with breast cancer: a systematic review and meta-analysis. Breast Cancer Res Treat. 2015;152(2):239-46.

24. McCormack L, Jones S, Coulter S. Demographic factors influencing nonurgent emergency department utilization among a Medicaid population. Health Care Manag Sci. 2016. Epub.

25. Moody-Thomas S, Celestin MD, Tseng TS, Horswell R. Patient tobacco use, quit attempts, and perceptions of the healthcare provider practices in a safety-net healthcare system. Ochsner J. 2013;13(3):367-74.

26. National Heart Lung and Blood Institute. Expert Panel Report 3 (EPR-3): Guidelines for the Diagnosis and Management of Asthma-Full Report 2007. August 28, 2007. Accessed 15 December 2015. Available at: http://www.nhlbi.nih.gov/guidelines/asthma/asthgdln.htm.

27. Nwabuo C, Dy S, Weeks K, Young J. Factors associated with appointment non-adherence among African-Americans with severe, poorly controlled hypertension. PLoS One. 2014;9(8):e103090.

28. Osterberg L, Blaschke T. Adherence to medication. N Engl J Med. 2005;353: 487-97.

29. Poisson T, Dallongeville J, Evans A, Ducimetierre P, Amouyel P, Yarnell J, Bingham A, Kee F, Dauchet L. Fruit and vegetable intake and smoking cessation. Eur J Clin Nutr. 2012;66(11):1247-53.

30. Price S, Bentley K. Psychopharmacology decision-making among pregnant and postpartum women and health providers: informing compassionate and collaborative care women's health. Womens Health. 2013:53(2):154-72.

31. Ramseir CA, Kobrehel S, Staub P, Sculean A, Lang NP, Salvi GE. Compliance of cigarette smokers with scheduled visits for supportive periodontal therapy. J Clin Periodontol. 2014;41(5):473-80.

32. Silva JA, Dourado I, Brito AM, Silva C. Factors associated with non-adherence to antiretroviral therapy in adults with AIDS in the first six months of treatment in Salvador, Bahia State, Brazil. Cad Saude Publica. 2015;31(6):1188-98.

33. Tobacco Free Maine [Internet]. Adult Tobacco Use Fact Sheet. 2013. Last accessed 15 August 2015. Available from http://www.tobaccofreemaine.org/ explore facts/documents/Adult-Tobacco-Use.pdf.

34. Uthman O, Magidson J, Safren S, Nachega J. Depression and adherence to antiretroviral therapy in low-, middle- and high-income countries: a systematic review and meta-analysis. Curr HIV/AIDS Rep. 2014;11(3):291-307.

35. Webb MS, Vanable PA, Carey MP, Blair DC. Medication adherence in HIVinfected smokers: the mediating role of depressive symptoms. AIDS Educ Prev. 2009:21(Suppl):94-105.

\section{Submit your next manuscript to BioMed Central and we will help you at every step:}

- We accept pre-submission inquiries

- Our selector tool helps you to find the most relevant journal

- We provide round the clock customer support

- Convenient online submission

- Thorough peer review

- Inclusion in PubMed and all major indexing services

- Maximum visibility for your research

Submit your manuscript at www.biomedcentral.com/submit 